\title{
Bioprospecting Potential of Ocimum basilicum for Access and Benefit Sharing Around Bahir Dar City Administration, West Gojam and Northwest Gondar, Amhara Region, Ethiopia
}

\author{
Amare Seifu Assefa ${ }^{*}$, Ashenafi Ayenew Hailu, Edeget Merawi Betsiha, Taye Birhanu Belay, \\ Abiyselassie Mulatu Gashaw, Yibrehu Emshaw Ketema
}

Genetic Resources Access and Benefit Sharing Directorate, Ethiopian Biodiversity Institute (EBI), Addis Ababa, Ethiopia

Email address:

ameseifu21@gmail.com (A. S. Assefa)

${ }^{*}$ Corresponding author

\section{To cite this article:}

Amare Seifu Assefa, Ashenafi Ayenew Hailu, Edeget Merawi Betsiha, Taye Birhanu Belay, Abiyselassie Mulatu Gashaw, Yibrehu Emshaw Ketema. Bioprospecting Potential of Ocimum basilicum for Access and Benefit Sharing Around Bahir Dar City Administration, West Gojam and Northwest Gondar, Amhara Region, Ethiopia. Advances in Bioscience and Bioengineering. Vol. 4, No. 4, 2016, pp. 35-42. doi: $10.11648 /$ j.abb.20160404.12

Received: July 18, 2016; Accepted: July 28, 2016; Published: August 12, 2016

\begin{abstract}
The genus Ocimum is positioned high among some of the amazing herbs for having vast medicinal potentialities. Ocimum basilicum L. belongs to the Lamiaceae family referred to as the 'King of Herbs' has been used extremely as a traditional medicine for various diseases. Therefore, the objective of this study was to assess the Bioprospecting potential of Ocimum basilicum for access and benefit sharing around Bahir Dar City Administration, West Gojam and Northwest Gondar Zones, Amhara Region, Ethiopia. Accordingly, an assessment was carried out in two Zones and Bahar Dar City Administration, in 100 randomly selected households in ten different Kebeles (the smallest administrative unit in Ethiopia). Based on the interview and field observation there were variations in the distribution of Ocimum basilicum in the study Kebeles. The result of this study showed that the distribution patterns of Ocimum basilicum in most of the study Kebeles was sparse. The result of this study also indicated that Ocimum basilicum used traditionally as flavoring and preservative agent, as perfume, as enhancer of concentration while studying or reading, as relieving agent for stress and depressions and as folk medicine in traditional therapies. Based on the traditional use of Ocimum basilicum as base line and other related experimental studies, the essential extracts of Ocimum basilicum used by the local people of the study area might have industrial applications for pharmaceuticals, food and cosmetics industries for access and benefit sharing. Although, Ocimum basilicum has high potential for pharmaceuticals, food and cosmetics industries, in the study area the farmers and the agricultural sectors give less attention to this sparsely distributed plant. Since Ocimum basilicum is sparsely distributed, any bioprospecting company can access the genetic resource by preparing their own farm or by tissue culture technique. Human activities and the annoying effects of climate change may lead to loss of this species unless appropriate measures are taken into consideration.
\end{abstract}

Keywords: Bioprospecting, Cosmetics, Flavoring agent, Ocimum basilicum, Pharmaceuticals, Preservative Agent

\section{Introduction}

The Convention on Biological Diversity [6] Secretariat defines bioprospecting as the exploration of biodiversity for commercially valuable genetic and biochemical resources. Bioprospecting or biodiversity prospecting is the exploration, extraction and screening of biological diversity and indigenous knowledge for commercially valuable genetic and biochemical resources. Advances in biotechnology and associated areas have increased the value of biodiversity and related knowledge of indigenous communities, and lent impetus to global bioprospecting activities. The Convention on Biological Diversity created a framework for regulation of such activities and replaced the existing regime of free access 
to bioresources with a framework where indigenous communities would be compensated for use of their knowledge, innovation, and practices [3, 9, 14].

Bioprospecting covers a wide range of commercial activities in different industrial sectors including pharmaceuticals, food, beverages, biotechnology, seed, crop protection, horticulture, botanical medicines and cosmetics and personal care. It provides valuable leads for new product development and many companies look for new applications of biological species that have not been studied earlier. As such, they enter into collaborative programmes with collectors in different countries to procure their needed supply of bio resources $[3,9,11]$.

Bioprospecting has also frequently been cited as a sustainable use of biodiversity that provide a motivation for conservation. Nevertheless, in the tropical, biodiversity-rich regions of the world, the level of bioprospecting is much below the potential, with the consequence of its limited impact on conservation. For areas with higher biodiversity, such as the tropics, bioprospecting may be an economic use of biodiversity that effectively promotes habitat protection. Nevertheless, the significance of bioprospecting for providing benefits for developing countries and its role in enhancing the protection of their biodiversity has been controversial. This controversy results, in part, from changing perceptions on who owns and who should benefit from biodiversity $[3,9,14]$.

Traditional medicines provide primary health care needs to almost $65-85 \%$ of the world's population, including developed nations. It is also estimated that about $39 \%$ of all 520 new approved drugs in 1983-1994 were natural products and out of that $74 \%$ were discovered as a result of bioprospecting from plants used in traditional medicines [3, 24]. But the search for plants as a source of potential candidate for drug development is still unsound. Out of 250,000 to 500,000 species available on earth only $1-10 \%$ is being potentially used [4]. It has been estimated that 14 to $28 \%$ of higher plant species are used medicinally and that $74 \%$ of pharmacologically active plant-derived components were discovered after following upon ethno- medicinal use of the plants $[3,9,24]$.

Aromatic plants occupy an important place among herbs and natural products. Their aroma is associated with the presence of essential oils, complex mixtures of volatile compounds, dominated by mono- and sesquiterpenes. In addition to essential oils, aromatic plants are characterized by the presence of plant phenolic compounds, primarily coumarins and phenylpropanoids that have been shown to possess multiple pharmacological activities [17, 20, 21, 25].

The genus Ocimum is ranked high among some of the astonishing herbs for having enormous medicinal potentialities. It is cultivated for its remarkable essential oil which exhibits many usages such as in medicinal application, herbs, culinary, perfume for herbal toiletries, aromatherapy treatment and as flavoring agent $[11,12,17,21,26]$. Ocimum basilicum $L$ belonging to the Lamiaceae family also referred to as the 'King of Herbs' has been used tremendously as traditional medicine for various ailments [2]. It is considered as one of the most important source of medicine and drugs due to the presence of various phytochemical active compounds like alkaloids, saponins, tannins, anthraquinone, flavonoids, steroids, terpenoids and cardiac glycosides $[7,8$, $18,21,30]$.

The chemical composition of the essential oil of Ocimum basilicumhas been studied since 1930s, and more than 200 chemical components have been identified so far [18]. However, less attention is given to the studies of Ocimum basilicum in Ethiopia and very few investigations have been undertaken since then.

Ocimum basilicumis the most known aromatic plant usually used during holiday since it is found mixed with fresh grass and used as traditional medicine (personal observation). From this observation, as a baseline, the essential extracts from Ocimum basilicum used by the local people of the study area might have an industrial application which is not properly and systematically utilized currently in Ethiopia. Moreover, most of the local community uses this genetic resource traditionally. Therefore, this research aims at bioprospecting the indigenous knowledge on Ocimum basilicum for industrial application and identifying potential distribution areas of the species around the study area so as to promote it for access and benefit sharing purposes and analyze the causative agent (if any) for the reduction of Ocimum basilicum or associated indigenous knowledge in the study area.

\section{Materials and Methods}

\subsection{Description of the Study Area}

The Amhara Region is located in the northwestern part of Ethiopia; its land area is estimated at about 170,000 kms. Amhara Region borders Tigray Region in the North, Afar in the East, Oromiya in the South, Benishangul-Gumuz in the Southwest and Sudan in the west. Based on the 2007 reports from the Central Statistical Agency [5] of Ethiopia, Amhara has an estimated total population of 20,136,000. Bahir Dar is the capital city of the Amhara Regional State. Amhara is divided into 11 'Zones', and 167 'Woredas' (districts). There are about 3,429 'Kebeles' [23].

North Gondar is a 'Zone' in Amhara Region. This 'Zone' is named for the city of Gondar, the capital of Ethiopia until the mid- $19^{\text {th }}$ Century, which has often been used as a name for the $20^{\text {th }}$ Century province of Begemider. North Gondar is bordered in the South by Lake Tana, West Gojjam, AgewAwi and the Benishangul-Gumuz Region, in the West by Sudan, in the North by the Tigray Region, in the East by Wag Hemra and in the Southeast by Debub Gondar. Based on the 2007 Census conducted by the Central Statistical Agency of Ethiopia this 'Zone' has a total population of 2,929,628, of whom 1,486,040 are men and 1,443,588 women [5].

West Gojjam is a 'Zone' in the Amhara Region of Ethiopia. West Gojjam is named after the former province of Gojjam. West Gojjam is bordered in the South by the Abay 
River which separates it from the Oromia Region and Benishangul-Gumuz Region, in the West by Agew Awi, in the Northwest by North Gondar, in the North by Lake Tana, and the Abay River which separates it from the Debub
Gondar, and in the East by East Gojjam . Based on the 2007 Census conducted by the Central Statistical Agency of Ethiopia this 'Zone' has a total population of 2,106,596, of whom 1,058,272 are men and 1,048,324 women [5].

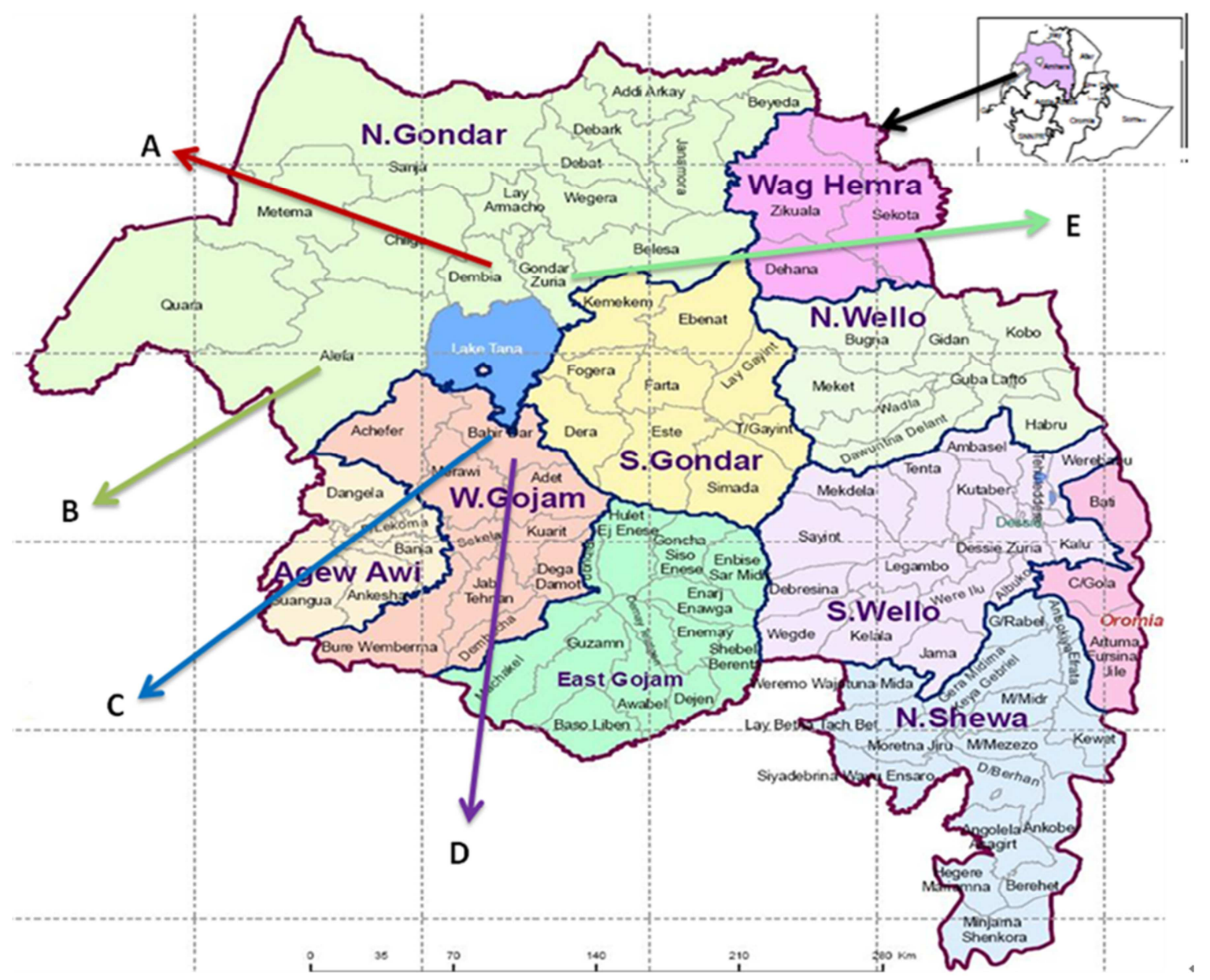

Fig. 1. Administrative map of the study area (A; Dembia, B; Alefa-Takusa, C; Bahir Dar City Administration, D; Bahir Dar Zuria, E; Gondar Zuria).

\subsection{Research Design}

The potential distribution of Ocimum basilicum was assessed from prioritized regional, zonal and districts annual reports. Checklists were given to the agricultural officers. Based on their report and previous field experiences, the areas were prioritized from the highest distribution to the relatively lower distribution.

Purposive sampling method was employed to identify potential Ocimum growing areas [29]. A total of 100 key informants (males and females) were systematically selected with the help of local administrators and local elderly people based on their knowledge or skills from 5'districts' (20 from each) for ethno-botanical data collection, 20 informants were selected from the 5 targeted sectors (4 from each) for collecting data of pharmaceutical, industrial, potential distribution and detailed study.

\subsection{Method of Data Collection}

This study was conducted between September 2015 and June 2016. The study focused on bioprospecting potentials of
Ocimum basilicum for access and benefit sharing around Bahir Dar City Administration, West Gojam and Northwest Gondar, Ethiopia. The study districts were selected purposively on the basis of the abundance of Ocimum bailicum with the help of information obtained from Regional, Zonal and District Agricultural Offices.

Based on the above selection criteria from the five districts, the study was conducted only on ten representative 'kebeles'. Two 'Kebeles' (the smallest administrative unit in Ethiopia) were selected from each district. Accordingly, from Bahir Dar City Administration, Zege 01 and Ura were selected; from West Gojjam, Bahir Dar Zuria district was selected. From this district, Wonjeta and Yigodi 'Kebeles' were selected. From North Gondar, three districts were selected, namely, Debiya, Takusa and Gondar Zuria. From each district, two 'Kebeles' were selected, namely, Guraba_Michale and Bata from Debiya district, Mekonta_Aybega and Chemerana_Banberawa from Takusa district and Layiye_Duge and Zengaj from Gondar Zuria district. From each 'Kebele', ten households were selected bringing the total number of sampled households to 100 . 
The primary data was collected through semi-structured interview, group discussion and field observation. Secondary data were obtained from the agricultural offices of the regions and literature review.

\subsection{Data Analysis and Interpretation}

The collected ethno-medicinal data was subjected to SPSS software version 21 or Excel spreadsheet and analyzed as well as interpreted using descriptive statistics (percentage and frequency) and inferential statistics. Linear Regression Analysis (using SPSS) was used to predict the value of a variable based on the value of another variable.

The age and education level of respondents were taken as the independent variables while the number of diseases treated by Ocimum basilicum reported by the respondents were taken as the predicted variable or dependent variable or outcome variable.

\section{Results and Discussions}

\subsection{Households Characteristics}

From the total respondents, $26 \%$ of the household's heads were aged between 18 and 35 years old, while most of the household heads $(71 \%)$ were aged between 36 and 65 years old, $3 \%$ of the households heads were aged greater than 65 years old. Regarding the sex of the respondents, most of them were males $(61 \%)$ and $39 \%$ of them were females. As to the education status of the households, $30 \%$ of them were uneducated, while $28 \%$ of the participants studied informal education, $33 \%$ of them studied primary (first cycle, $1-4$ and Second cycle, 5-8) and 9\% of them studied Secondary high School (9-10) education. The educational status of the households was from uneducated households up to Secondary high School (9-10). Assessment in the job category of the respondents indicated that all of the respondents were farmers.

Concerning to the economic status of the respondents, most of them $(71 \%)$ had medium income, $24 \%$ of them had higher income and 5\% of them had low income. Regarding to the marital status of the respondents, $93 \%$ of them were married, $3 \%$ of them were unmarried and $4 \%$ of them were divorced. As to number of years the respondents were living in the study area, most (78\%) of them were living $31-60$ years while $18 \%$ were living $11-30$ years; 3\% were living greater than 60 years and $1 \%$ of the respondents were living less than 10 years in the study 'kebeles'.

\subsection{Distribution of Ocimum basilicum in the Study Area}

There were variations in the distribution of Ocimum basilicum in the study 'Kebeles'. Almost half of the respondents (54\%) in the study 'Kebeles' had Ocimum basilicum on their land and $46 \%$ of them reported as they had no Ocimum basilicum on their land. Majority of the respondents reported that Ocimum basilicum in most of the study 'kebeles' was sparsely distributed. Human activities and the annoying effects of climate change may lead to loss of this species unless appropriate measures are taken (Table 1).

Table 1. Respondents' statements whether they have or not Ocimum basilicum on their land.

\begin{tabular}{llll}
\hline & Frequency & Percent & Cumulative Percent \\
\hline Yes & 54 & 54 & 54.0 \\
No & 46 & 46.0 & 100.0 \\
Total & 100 & 100.0 & \\
\hline
\end{tabular}

Regarding the growth form of Ocimumbasilicum, most of the respondents $(63 \%)$ reported its existence in the wild, $7 \%$ reported it as cultivated form, \& $30 \%$ reported it as wild and cultivated forms (Table 2).

Table 2. Respondents statements about the growth form of Ocimum basilicum.

\begin{tabular}{llll}
\hline Growth form & Frequency & Percent & Cumulative Percent \\
\hline Cultivated & 7 & 7.0 & 7.0 \\
Wild & 63 & 63.0 & 70.0 \\
Both & 30 & 30.0 & \\
Total & 100 & 100.0 & 100.0 \\
\hline
\end{tabular}

\subsection{The Potential Use and Industrial Opportunities of Ocimum basilicum}

The genus Ocimum is cultivated for its remarkable essential oil which exhibits many usages such as in medicinal application, herbs, culinary, perfume for herbal toiletries, aromatherapy treatment and as flavoring agent $[12,19,30]$.

\subsubsection{Ocimum basilium as Food Preservative and Flavoring Agents}

Regarding to the use of Ocimum basilium as flavoring and preservative agent, a little below half of the respondents $(45 \%)$ used the plant as flavoring and preservative agent (of which $18 \%$ used it as preservative and $27 \%$ as flavoring agent). They used the plant as flavoring agent in tea and coffee and used it as flavoring and preservative agent in butter. $30 \%$ of the respondents reported Ocimum basilicum as it had no flavoring and preservative uses and $25 \%$ of them had no information about its use as flavoring and preservative agent. [19] reported that the essential components of Basil are frequently used as flavoring and preservative agents in soups, desserts, pickles, pizza, spaghetti sauce, egg, cheese dishes, tomato juice, dressings, confectionery, salads, meat products etc. The results of the current study and the previous study by [19] confirmed that Ocimum basilicum has been used as preservative and flavoring agent for various foods.

Basil (Ocimum basilicum L.) was reported as an aromatic herb that is used extensively to add a distinctive aroma and flavor to food; its fresh or dried leaves were reported for use as a spice and its essential oils extracted from fresh leaves and flowers were reported for use as aroma additives in foods, pharmaceuticals and cosmetics [27].

\subsubsection{Ocimum basilium as a Traditional Perfume and a Stress-Relieving Agent}

According to the respondents' report, the people in the study area used Ocimum basilicum to impart a pleasant smell 
to their body or clothes. Of the total respondents, $16 \%$ of them reported that they use Ocimum basilicum as a traditional perfume to their body or clothes and houses/rooms. They put its leaves under the beds/sheaths and sleep on it which helps to change the smell of the bed room. They also used the plant to attract honeybees.

The traditional use of Ocimum basilicum as a perfume by the respondents has been supported by [13] which studied about the aroma profiles of 5 different cultivars grown under both organic and conventional conditions. In addition [22] also reported about the extensive use of the oil of sweet basil in condimentary products, cosmetics, and toiletry, perfumery and confectionery industries which is almost analogous to the current assessment study.

Some respondents in the study area $(11 \%)$ reported about the role of Ocimum basilicum smelly or aromatic leaves in boosting concentration power while studying or reading and relieving stress and depressions. [10] indicated its sedative, hypnotic, and anticonvulsant activities of Ocimum basilicum essential oil.

The results of the current study showed that Ocimum basilicum has industrial applications in cosmetics and perfumery industries, and used as preservative and flavoring agents in pharmaceutical and food industries.

\subsubsection{Ethno-medicinal and Ritual Significance of Ocimum basilicum}

Based on the interview Ocimum basilicum has medicinal and religious (ritual) significances in the study area. [1] showed that ethanol extracts of Ocimum basilicum has an antimicrobial effect against nine strains in the genera Acinetobacter, Bacillus, Escherichia, and Staphylococcus.

Most of the respondents replied that Ocimum basilicum has medicinal value. Of the total respondents, $47 \%$ of them reported that they use Ocimum basilicum to treat human diseases, $23 \%$ of them used it to treat diseases of honeybees and $12 \%$ of them believed that Ocimum basilicum used to treat evil spirits (cultural believe) and the remaining respondents $(18 \%)$ had no information about the medicinal use of Ocimum basilicum (Fig. 2). They also used the plant as a folk remedy against various ailments such as feverish illnesses, poor digestion, nausea, abdominal cramps, gastroenteritis, migraine, insomnia, depression, gonorrhea, dysentery, chronic diarrhea exhaustion, Copraet al., 1985, cited in [1] which are almost similar to the current study.

According to the respondents' reports the people in the study area used Ocimum basilicum to treat diseases traditionally such as common cold, bacterial diseases, stomachache, tonsillitis and malaria. The current assessment studyhas been supported by many experimental studies. [22] verified that basil essential oils and their principal constituents were found to exhibit antimicrobial activity against a wide range of Gram-negative and Gram-positive bacteria, yeast, and mould. [2] also studied about the presence of triterpenoids, flavanoids and polyphenols in leaves of Ocimum basilicum L. These results could be of immense help to validate the several medicinal properties of

\section{Ocimum basilicum L.}

Moreover, [18] who conducted an immunomodulatory activity of aqueous leaf extract of Ocimum basilicum L indicated the plant's potent immune stimulant, stimulating specific and non-specific immune mechanisms. The immunostimulatory activity of Ocimum basilicum was attributed to the presence of flavonoids (quercetin), alkaloids, tannins, saponin glycosides and phenolic compound. The results of this experimental study also support the current assessment study.

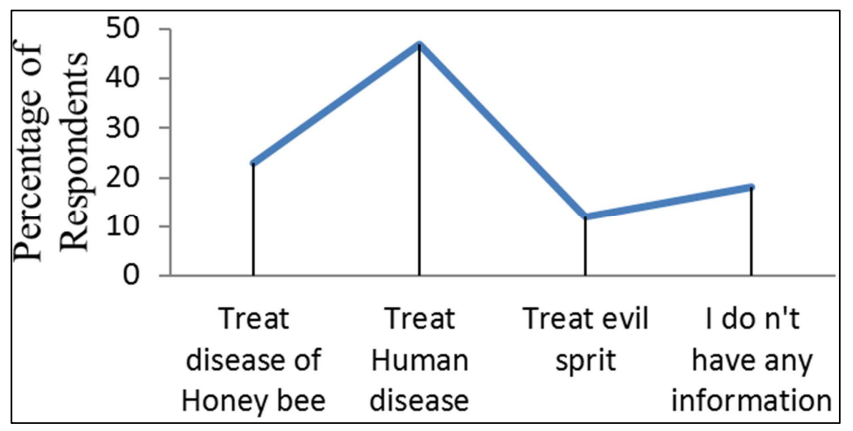

Fig. 2. Traditional Medicinal use of Ocimum basilicum.

Some respondents in the study 'Kebele' (9\%) reported that the root of Ocimum basilicum (chopped root of Ocimum basilicummixed with water) is used to treat lactation failure in humans and cows. Similarly, leaves and flowering parts of Ocimumbasilicum are traditionally used as antispasmodic, carminative, digestive, galactogogue, stomachic, and tonic agent, Duke and Ayensu, 1985, cited in [1]. The previous and the current study mightsuggest that Ocimum basilicumcontains a galactogoguethat promote lactation in humans and other animals.

Since Ocimum basilicum is sparsely distributed, any bioprospecting company can access the genetic resource by preparing their own farm or by tissue culture technique.

\subsection{Preparation Method and Route of Administration of Ocimum basilicum for Traditional Medicinal Use}

Most of the respondents reported about the use of Ocimum basilicum in fresh forms in traditional medicinal preparations. Similarly, [15] and [16] reported as the majority of the people use plants in fresh form for traditional medicinal preparation while the people use very few medicinal plants in both fresh and dried forms. Though, cold water, coffee, butter, salt, honey and milk were reported to be mixed with Ocimum basilicum during traditional medicinal preparation, water remains to be the most frequently used 'solvent' in the preparation of remedies.

The route of administration/application of Ocimum basilicum as traditional medicine was reported to be drinking (oral), smelling (nasal) and smearing (dermal). The most common route of administration was reported to be drinking (oral) $(35 \%)$ followed by smearing (dermal) $(15 \%)$. This could be due to the high incidence of digestive disorder and skin-associated diseases (dermatitis) in the area. This result is supported by similar studies $[15,16]$. 


\subsection{Relationship Between Respondent's Age \& Number of Diseases Treated by 0 . basilicum}

The study proved that there were considerable variations in the numbers of diseases treated by Ocimum basilicum mentioned by teenagers and elders which gives information necessary to predict number of diseases treated by $O$. basilicum (knowledge of respondents on medicinal use of $O$. basilicum) with respect to age. One can notice that both numbers of diseases treated by $O$. basilicum and respondent's age contribute to the model. As age of the respondents increases number of diseases treated by $O$. basilicum also increases. The older persons know more diseases treated by $O$. basilicum than the teenagers. Hence, the regression equation can be presented as $\mathrm{Y}:=0.129 \mathrm{X}-4.203$, where $\mathrm{Y}$ is number of diseases treated by $O$. basilicum and $\mathrm{X}$ is age of the respondents. $\mathrm{R}^{2}$ value indicates how much of the dependent variable can be explained by the independent variable. In this case, $\mathrm{R}^{2}=0.717$ or $71.7 \%$ of the dependent variable can be explained by the independent variable. The result of this study showed that there is a strong positive linear relationship between number of diseases treated by $O$. basilicum identified by the respondents and age of the respondents $(\mathrm{R}=0.847)$ (Fig. 3). [16] and [28] reported almost similar results concerning ethno-botanical studies of other medicinal plants.

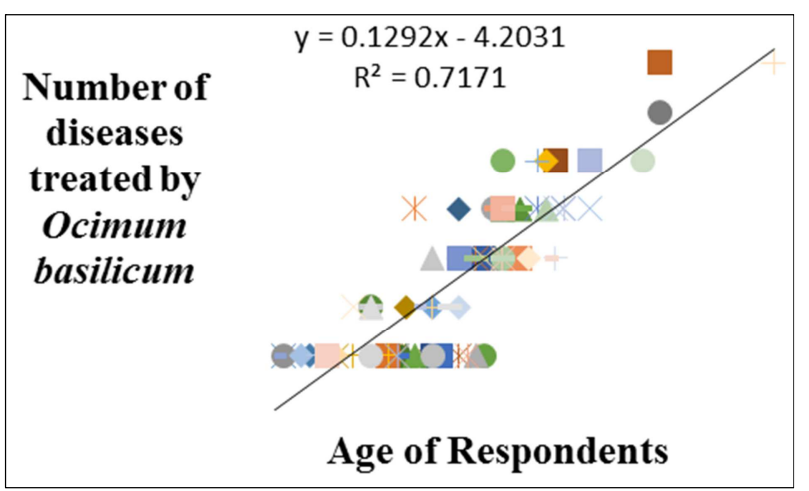

Fig. 3. Relationship between number of diseases treated by $O$. basilicum and Age of Respondents $\left(R^{2}=0.717, p<0.0005\right)$.

\subsection{Relationship of Educational Statusof Respondents and Number of Diseases Treatedby $O$. basilicum}

The results indicated that there is difference in traditional medicinal knowledge on $O$. basilicum among educated and uneducated members of the respondents which gives information necessary to predict number of diseases treated by of $O$. basilicum with respect to the educational status of respondents. Both numbers of diseases treated by $O$. basilicum and the educational level of respondents contribute to the model. As the educational level of the respondents increases, the number of diseases treated by $O$. basilicum decreases. The younger generation does not give attention to the indigenous knowledge. Hence, the regression equation can be presented as: $\mathrm{Y}=-0.222 \mathrm{X}+2.393$, where $\mathrm{Y}$ is number of diseases treated by $O$. basilicum and $\mathrm{X}$ is educational status of the respondents. In this case, $\mathrm{R}^{2}=0.279$, or $27.9 \%$ indicated that there is a justification for the existence of too much difference in traditional medicinal knowledge on $O$. basilicum among respondents. The regression equation and Pearson correlation (-0.529) indicated the existence of strong negative linear relationship between number of diseases treated by Ocimum basilicum and educational status of the respondents (Fig. 4). Similar results were recorded by [16] and [28] for different medicinal plants.

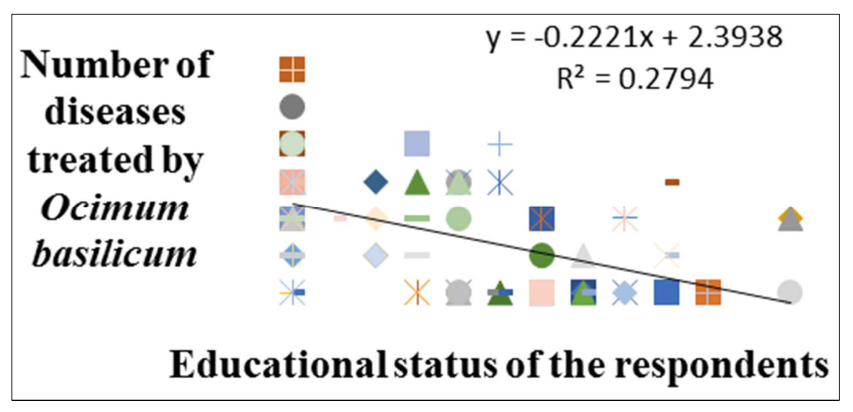

Fig. 4. Relationship of educational status of respondents and number of diseases treated by $O$. basilicum $\left(R^{2}=0.279, p<0.0005\right)$.

\section{Conclusions and Recommendations}

Ocimum basilicum has high bioprospecting potential for pharmaceuticals, food and cosmetics industries. Commercializing and bioprospecting this medicinal, aromatic, food (flavoring and preservative agent) and cosmetics plant, would not only increase the Ethiopia's economic growth, but also contribute to the global stock of pharmaceuticals, food and cosmetics industries. Traditional medicinal plants have lots of potentials, in terms of the provision for the primary health care as well as in the discovery of new drugs.

Developing countries such as Ethiopia are enormously rich in biodiversity and traditional medicinal knowledge but lack the technologies and monetary resources to significantly investigate and add value to them, but the developed countries are rich in technologies and monetary resources but lacks in the natural resources and the traditional medical knowledge. As a developing country, Ethiopia has to collaborate with developed nations and interested pharmaceutical, cosmetics and other companies, and jointly explore them strategically (builds the fair and equitable sharing of benefits).

Although Ocimum basilicum has high potentials for pharmaceuticals, food and cosmetics industries, the result of this study indicates that in the study area the farmers and the agricultural sectors give less attention to this sparsely distributed plant. Since Ocimum basilicum is sparsely distributed, any bioprospecting company can access the genetic resource by preparing their own farm or by tissue culture technique. Human activities and the annoying effects of climate change may lead to loss of this species unless appropriate measures are taken. 


\section{Acknowledgments}

The people of Bahir Dar City Administration, West Gojam and North Gonder, Amhara Region who gave us information are gratefully acknowledged. We are grateful to Ethiopian Biodiversity Institute (EBI) for financial support during fieldwork. We are also grateful to Agricultural worker in Bahir Dar City Administration, West Gojam and North Gondar who helped us in different ways. Finally, we are indebted very much to Bahir Dar Zuria, Debiya, Takusa and Gondar Zuria districts farmers for their unreserved willingness to share their time and knowledge with us and for allowing us to mess up their well-kept gardens.

\section{References}

[1] Abiguzel, A., Gulluce, M., Sengul, M., Ogutcu, Sahin, F. and Karaman, I. (2005). Antimicrobial effects of Ocimum basilicum (Labiatae) extract. Turk. J. Biol. 29: 155-160.

[2] Adtani, P., Malathi, N. and Chamundeeswari, D.(2014). Pharmacognostic evaluation of leaves of Ocimum basilicum Linn: the Lamiaceae family. Journal of Chemical and Pharmaceutical Sciences 7 (3): 250-253.

[3] Afreen, S. and Abraham, B. P. (2009). Bioprospecting: Promoting and Regulating Access to Genetic Resources and Benefit Sharing. Decision 36 (3): 121-158.

[4] Arora, D. S., Onsare, J. G. and Kaur, H. (2013). Bioprospecting of Moringa (Moringaceae): Microbiological. Journal of Pharmacognosy and Phytochemistry 1 (6): 193-215.

[5] Central Statistical Agency (CSA)(2015). The 2015 (2007 E. C.) Population and housing census: Result of Ethiopia. Central Statistical Agency. Addis Ababa, Ethiopia.

[6] Convention on Biological Diversity (CBD) (1992). United Nations.

[7] De Barros, N. A., Rocha, R. R., de Assis, A. R. and Mendes, M. F.(2013). Extraction of basil oil (Ocimum basilicum L.) using supercritical fluid. III Iberoamerican Conference on Supercritical Fluids. Cartagena de Indi as, Colombia.

[8] Dev, N., Das, A. K., Hossain, M. A. and Rahman, S. M. M. (2011). Chemical compositions of different extracts of Ocimum basilicum leaves. J. Sci. Res. 3 (1): 197-206.

[9] Harvey, A. L. and Gericke, N. (2011). Bioprospecting: Creating a value for Biodiversity. In: Research in Biodiversity - Models and Application, Chap. 15 (Pavlinov, I. Y., ed.) In Tech, Science, Technology and Medicine open access publisher.

[10] Ismail, M. (2006). Central properties and chemical composition of Ocimum basilicum Essential Oil. Pharmaceutical Biology (Egypt) 44 (8): 619-626.

[11] Joshi, S. V., Bothara, S. B., S and Surana, S. J. (2011). Evaluation of aqueous extract of Ocimum sanctum in experimentally induced Parkinsonism. J. Chem. Pharm. Res 3 (1): 478-487.

[12] Kaurinovic, B., Popovic, M., Vlaisavljevic, S. and Trivic, S. (2011). Antioxidant capacity of Ocimum basilicum L. and Origanumvulgare L. extracts. Molecules 16: 7401-7414.
[13] Klimankova, E., Holadova', K., Hajslova, J., Cajka, T., Poustka, J. and Koudela, M. (2008). Aroma profiles of five basil (Ocimum basilicum L.) cultivars grown under conventional and organic Conditions. Food Chemistry 107: 464-472.

[14] Kursar, T. A., Capson, T. L. Cubilla-Rios, L. Emmen, D. A., Gerwick, W., Gupta, M. P., Heller, M. V., McPhail, K., Ortega-Barría, E. Quiros, D. I., Romero, L. I., Solis, P. N. and Coley, P. D. (2007). Linking insights from ecological research with bioprospecting to promote conservation, enhance research capacity, and provide economic uses of biodiversity. In: Tropical Forest Community Ecology, pp. 429-441 (Carson, W. P. and Schnitzer, S. A., eds.) Wiley-Blackwell, West Sussex, UK.

[15] Melesse Maryo, Sileshi Nemomissa and Tamirat Bekele (2015). An ethnobotanical study of medicinal plants of the Kembatta ethnic group in enset-based agricultural landscape of Kembatta Tembaro (KT) Zone, Southern Ethiopia. Asian Journal of Plant Science and Research 5 (7): 42-61.

[16] Mersha Ashagre Eshete (2011). Ethnobotanical study of Medicinal Plants in Guji Agro- pastorilists, Blue Hora District of Borana Zone, OromiaRegion. Addis Ababa University. MSc. Thesis.

[17] Murthy, K. N., Nagendra, K., Uzma, F., Soumya, K. and Srinivas, C. (2014). Efficiency of Ocimum sanctum L. leaf extracts against bacterial wilt of tomato caused by Ralstonia solanacearum in tomato. Int. J. Curr. Microbiol. App. Sci. 3 (12): 234-245.

[18] Nahak, G. and Sahu, R. K. (2014). Immunomodulatory activity of aqueous leaf extracts of Ocimum basilicum Linn in Clariasbatrachus. International Journal of Pharmacy and Pharmaceutical Sciences 6 (6): 433-440.

[19] Ozcan, M. and Chalchat, J.-C.(2002). Essential oil composition of Ocimum basilicum L. And Ocimum minimum L. in Turkey. Czech J. Food Sci. 20 (6): 223-228.

[20] Saha, S., Dey, T. and Ghosh, P. (2010). Micropropagation of Ocimum kilim and scharicum Guerke (Labiatae). ACTA BIOLOGICA CRACOVIENSIA Series Botanical 52 (2): 5058.

[21] Sajjadi, S. E. (2006). Analysis of the essential oils of two cultivated basils (Ocimum basilicum L.) from Iran. DARU Journal of Pharmaceutical Sciences 14 (3): 128-130.

[22] Sastry, K. P., Kumar, R. R. A. N., Kumar, A. N., Sneha, G. and Elizabeth, M. (2012). Morpho-chemical description and antimicrobial activity of different Ocimum species. Plant Develop. 19: 53-64.

[23] Save the Children (2013). Amhara Regional State, Area Brief. Ethiopia.

[24] Silva, M. S. P., Brand ao, D. O., Chaves, T. P., Formiga Filho, A. L. N., Costa, E. M. M. B., Santos, V. L. and Medeiros, A. C. D. (2012). Study Bioprospecting of Medicinal Plant Extracts of the Semiarid Northeast: Contribution to the Control of Oral Microorganisms. Evidence-Based Complementary and Alternative Medicine 2012, Article ID 681207, 6 pages, 2012. doi: 10.1155/2012/681207.

[25] Singh, V., Amdekar, S. and Verma, O. (2010). Ocimum Sanctum (Tulsi): Bio-pharmacological activities. A Review. Pharmacology 1 (10): WMC001046. 
[26] Sunitha, K. and Begum, N. (2013). Immunomodulatory activity of methanolic extract of Ocimum americanum seeds. International Journal of Research in Pharmacy and Chemistry (India) 3 (1): 95-98.

[27] Telci, I., Elmastas, M. and Sahin, A. (2009). Chemical composition and antioxidant activity of Ocimum minimum essential oils. Chem. Nat. Compd. 45: 568-571.

[28] Tesfaye Awas and Sebsebe Demissew (2009). Ethnobotanical study of medicinal plants in Kafficho people, southwestern Ethiopia. In: Proceedings of the $16^{\text {th }}$ International Conference of Ethiopian Studies, pp. 711-726 (Ege, S., Aspen, H., Birhanu Teferra and Shiferaw Bekele, eds.) Trondheim.

[29] Tongco, M. D. C. (2007). Purposive sampling as a tool for informant selection. A journal of plants, people, and applied research. Ethnobotany Research and Applications 5: 147-158.

[30] Vani, S. R, Cheng, S. F. and Chuah, C. H. (2009). Comparative Study of Volatile Compounds from Genus Ocimum. American Journal of Applied Sciences 6 (3): 523528. 